\title{
JORNADA DIÁRIA DE TRABALHO COMO CRITÉRIO DE DIMENSIONAMENTO ECONÔMICO PARA SISTEMAS DE IRRIGAÇÃO POR PIVÔ CENTRAL
}

Caio Vinicius Leite ${ }^{1}$, José Alves Júnior ${ }^{2}$, Marcelo Rossi Vicente ${ }^{3}$, Adão Wagner Pego Evangelista ${ }^{4}$ \& Derblai Casaroli ${ }^{5}$

1 - Mestre em Engenharia Agrícola, Professor do IFB - Campus Planaltina, caio.leite@ifb.edu.br

2 - Doutor em Agronomia, Professor da UFG - Campus Samambaia, josealvesufg@yahoo.com.br

3 - Doutor em Engenharia Agrícola, Professor do IFNMG - Campus Salinas, marcelo.vicente@ifnmg.edu.br

4 - Doutor em Engenharia Agrícola, Professor da UFG - Campus Samambaia, awpego@bol.com.br

5 - Doutor em Agronomia, Professor da UFG - Campus Samambaia, derblaicasaroli@yahoo.com.br

\section{Palavras-chave:}

Aspersão

custo de energia

otimização

vazão específica

\section{RESUMO}

Considerando a relevância da irrigação por sistema de pivô central no Brasil e sua constante expansão, especialmente na Região Centro-Oeste, este trabalho buscou avaliar critérios de dimensionamento de pivô central que minimizem o custo total da irrigação por meio da otimização de sua vazão específica. Tendo em vista que a energia é um dos principais custos da irrigação e que a adequação tarifária permite redução dos custos com este insumo em função das diferentes modalidades de tarifas existentes, foi proposta uma metodologia em que diferentes jornadas diárias de operação foram avaliadas, a fim de se encontrar aquela que gere o menor custo total, de forma a equilibrar os custos de energia com os custos de implantação de um pivô central. Os resultados mostraram que o custo total mínimo foi obtido para o menor diâmetro da linha lateral, $65 / 8$ ", e maior jornada diária de trabalho, $24 \mathrm{~h} \mathrm{~d}^{-1}$, o que leva a uma menor vazão específica $\left(0,822 \mathrm{~L} \mathrm{~s}^{-1} \mathrm{ha}^{-1}\right)$, considerando a possibilidade de enquadramento no subgrupo B2 Rural. Com o enquadramento em tarifa horo sazonal, o menor custo anual total foi obtido para o maior diâmetro de linha lateral, 8 ", jornada de trabalho de $21 \mathrm{~h} \mathrm{~d}^{-1}$ e vazão específica de 0,939 $\mathrm{L} \mathrm{s}^{-1} \mathrm{ha}^{-1}$, sendo as tarifas Azul e Verde mais vantajosas do que a convencional.

\section{Keywords:}

Energy cost

optimization

sprinkling

system capacity

\section{DAILY OPERATION TIME AS CRITERION OF ECONOMIC DIMENSIONING TO IRRIGATION SYSTEMS BY CENTRAL PIVOT}

\section{ABSTRACT}

Considering the relevance of central pivot irrigation in Brazil and its recent expansion, especially in the Center-West Region, the aim of this was to evaluate central pivot dimensioning criteria that minimize the total cost of irrigation, through the optimization of the system capacity. Energy is one of the main costs of irrigation, so its rate adequacy allows the reduction of the consumption costs due to different categories of energy rates. Thereby, a methodology was proposed in which different daily operation times were evaluated in order to find the one that manages the lowest total cost in order to balance the energy costs with the costs of assembling a central pivot. The results showed that the minimum total cost was obtained for the smallest lateral line diameter, 6 $5 / 8$ ", and the biggest daily operation time, $24 \mathrm{~h} \mathrm{~d}^{-1}$. It leads to a smaller system capacity of 0.822 $\mathrm{L} \mathrm{s}^{-1} \mathrm{ha}^{-1}$, since it is possible to fit the equipment into the B2 Rural subgroup. Under a seasonal and hourly energy rate, the lowest total cost was obtained for the largest lateral line diameter, 8", a daily operation time of $21 \mathrm{~h} \mathrm{~d}^{-1}$ and a system capacity of $0.939 \mathrm{~L} \mathrm{~s}^{-1} \mathrm{ha}^{-1}$, in which the Blue and Green energy rates are more favourable than the conventional one. 
JORNADA DIÁRIA DE TRABALHO COMO CRITÉRIO DE DIMENSIONAMENTO ECONÔMICO PARA SISTEMAS DE...

\section{INTRODUÇÃO}

A área irrigada por pivô central é bastante significativa no Brasil, sendo aproximadamente 1,275 milhão de hectares (ANA \& EMBRAPA, 2017), 20,56\% da área total irrigada no Brasil (ANA, 2016). Esse sistema de irrigação tem sido bastante usado na região Centro-Oeste do país, especialmente pelas características de produção da região, que contam com grandes áreas cultivadas, principalmente por culturas anuais, declividade suave e uniforme, alto grau de tecnificação e mecanização das propriedades e disponibilidade de água.

No entanto, o agravamento da crise hídrica no país nos últimos anos tem limitado a expansão da agricultura irrigada, o que evidencia a importância do uso racional da água e da energia elétrica na agricultura.

As atividades de irrigação e aquicultura são beneficiadas com descontos especiais nas tarifas de energia elétrica para o consumo compreendido entre $21 \mathrm{~h} 30 \mathrm{~min}$ e $6 \mathrm{~h}$, por se enquadrarem como unidades consumidoras da Classe Rural (BRASIL, 2002). Os valores dos descontos variam conforme a região do país e o subgrupo tarifário, numa faixa de 60 a 90\% (ANEEL, 2010). Esse benefício cria oportunidades para racionalização dos custos da energia, caso o sistema de irrigação possa operar majoritariamente dentro do horário reservado, comumente denominada irrigação noturna. Assim, os critérios usados no dimensionamento do sistema, especialmente a jornada de trabalho e a lâmina aplicada que definem a vazão específica de projeto, tornam-se fundamentais para adequação dos sistemas a essa situação.

O critério de dimensionamento mais usual para sistemas de irrigação é o prolongamento da jornada diária de trabalho para aplicar uma lâmina correspondente à evapotranspiração diária da cultura, a fim de se reduzir a potência requerida pela instalação de bombeamento. Este critério visa notadamente diminuir os custos fixos de implantação e facilitar a captação direta de água pela redução da vazão específica de projeto.
Ocasionalmente, esse critério limita a capacidade de um pivô central para atender demandas de pico muito além dos valores de evapotranspiração médios para as condições climáticas da região, conferindo baixa flexibilidade ao manejo da irrigação.

Com a possibilidade de adequação tarifária, em que as tarifas de energia variam de acordo com o horário, a época do ano e os componentes de demanda e consumo, torna-se possível avaliar novos critérios que permitam a redução do custo total por meio da redução do custo de energia, garantindo que a demanda dos cultivos seja satisfeita, evitando déficit hídrico e queda de produtividade. À medida que a jornada diária de trabalho é reduzida, aumenta-se o custo de implantação do sistema devido ao aumento da vazão de projeto, podendo haver necessidade de construção de barragens para armazenamento de um maior volume de água. Por outro lado, ao se aumentar a jornada de operação, o aproveitamento da tarifa noturna, mais barata, fica comprometida. A análise de critérios de dimensionamento que visam reduzir esses custos contribui para a tomada de decisão dos irrigantes que se propõe a adquirir novos sistemas de irrigação, substituir ou redimensionar equipamentos já existentes, especialmente em regiões com limitado acesso ao fornecimento de energia.

Este trabalho buscou avaliar a viabilidade econômica de diferentes vazões específicas de projeto e modalidades tarifárias para reduzir o custo total da irrigação em comparação aos critérios convencionais de dimensionamento de sistema de pivô central.

\section{MATERIAL E MÉTODOS}

O trabalho foi desenvolvido para o município de Formosa-GO, localizado na latitude de $15^{\circ} 32^{\prime}$ '57" $\mathrm{S}$, longitude de $47^{\circ} 20^{\prime} 19^{\prime \prime} \mathrm{O}$ e altitude de $935 \mathrm{~m}$. As normais climatológicas para Formosa-GO (INMET, 2009) estão apresentadas na Tabela 1. A evapotranspiração de referência $\left(\mathrm{ET}_{\mathrm{o}}\right)$ foi obtida pelo método de Hargreaves (2003). 
Tabela 1. Normais climatológicas (1961-1990) e ET para Formosa-GO.

\begin{tabular}{|c|c|c|c|c|c|c|c|c|c|c|c|c|c|}
\hline Meses & JAN & FEV & MAR & $\mathrm{ABR}$ & MAI & JUN & JUL & AGO & SET & OUT & $\mathrm{NOV}$ & DEZ & ANO \\
\hline $\mathrm{T}_{\text {méd }}\left({ }^{\circ} \mathrm{C}\right)$ & 22,2 & 22,4 & 22,5 & 22 & 20,7 & 19,5 & 19,3 & 21,3 & 22,8 & 22,9 & 22,3 & 22,1 & 21,7 \\
\hline $\mathrm{T}_{\text {max }}\left({ }^{\circ} \mathrm{C}\right)$ & 27,0 & 27,7 & 28,0 & 27,7 & 27,2 & 26,2 & 26,2 & 28,5 & 29,7 & 28,8 & 27,7 & 27,1 & 27,7 \\
\hline $\mathrm{T}_{\min }\left({ }^{\circ}\right)$ & 18,4 & 18,5 & 18,4 & 17,6 & 15,8 & 13,9 & 13,3 & 14,5 & 16,5 & 17,7 & 18,1 & 18,4 & 16,8 \\
\hline Ins (h) & 156,8 & 163,0 & 187,2 & 216,0 & 243,1 & 245,9 & 260,6 & 267,1 & 213,4 & 181,5 & 151,5 & 119,9 & $2.406,0$ \\
\hline UR (\%) & 80,0 & 78,0 & 78,0 & 75,0 & 70,0 & 65,0 & 58,0 & 51,0 & 53,0 & 67,0 & 76,0 & 81,0 & 69,3 \\
\hline $\mathrm{Vv}\left(\mathrm{m} \mathrm{s}^{-1}\right)$ & 1,24 & 1,34 & 1,17 & 1,27 & 1,31 & 1,50 & 1,70 & 1,67 & 1,62 & 1,42 & 1,32 & 1,23 & 1,40 \\
\hline Ppt (mm) & 242,9 & 207,4 & 173,6 & 116,7 & 28,9 & 2,6 & 6,8 & 10,1 & 36,4 & 134,8 & 187,6 & 300,1 & $1.447,9$ \\
\hline $\mathrm{ET}_{\mathrm{o}}\left(\mathrm{mm} \mathrm{d}^{-1}\right)$ & 4,6 & 4,6 & 4,5 & 4,0 & 3,6 & 3,3 & 3,5 & 4,3 & 4,9 & 5,0 & 4,8 & 4,6 & 4,3 \\
\hline
\end{tabular}

Para o dimensionamento dos sistemas de irrigação por pivô central, foi necessário definir a vazão específica de projeto, conforme a Equação 1 a seguir.

$q=2,778 \times \frac{L B}{J}$

em que,

$\mathrm{q}=$ vazão específica de projeto, $\mathrm{em} \mathrm{Ls}^{-1} \mathrm{ha}^{-1}$;

$\mathrm{LB}=$ lâmina bruta de irrigação, em $\mathrm{mm} \mathrm{d}^{-1}$; e $\mathrm{J}=$ jornada diária de trabalho, em $\mathrm{h} \mathrm{d}^{-1}$.

A lâmina bruta de irrigação (LB), a fim de atender a necessidade dos cultivos, foi obtida conforme a Equação 2.

$\mathrm{LB}=\frac{\mathrm{K}_{\mathrm{c}} \times \mathrm{ET}_{\mathrm{o}}}{\mathrm{Ei}}$

em que,

$\mathrm{K}_{\mathrm{c}}=$ coeficiente de cultivo, adimensional;

$\mathrm{ET}_{\mathrm{o}}=$ evapotranspiração de referência, em $\mathrm{mm} \mathrm{d}^{-1}$; e $\mathrm{Ei}=$ eficiência de irrigação estimada, adimensional.

O município de Formosa-GO usa intensivamente o sistema de irrigação por pivô central para a produção de grãos, de modo que foram escolhidas culturas usuais para os sistemas de produção típicos da região, conforme a Tabela 2, baseada nos resultados apresentados por Allen et al. (1998).

Tabela 2. Coeficientes de cultivo máximos para as culturas selecionadas e ciclo de cultivo

\begin{tabular}{ccc}
\hline Cultura & $\mathrm{K}_{\mathfrak{c}}$ & Ciclo (dias) \\
\hline Feijão (Phaseolus & 1,15 & 100 \\
vulgaris) & & 150 \\
Milho (Zea mays) & 1,20 & 100 \\
Soja (Glycine max) & 1,15 & \\
\hline
\end{tabular}

Para definição da lâmina bruta de irrigação, foi empregado o valor do maior coeficiente de cultivo dentre as culturas selecionadas, em sua fase de maior demanda, milho( $\left.K_{c}=1,20\right)$. A eficiência de irrigação estimada para o pivô central, foi de $85 \%$, de acordo com Mantovani et al. (2009). A $\mathrm{ET}_{\mathrm{o}}$ considerada também foi para o período de maior demanda, igual a $5,0 \mathrm{~mm} \mathrm{~d}^{-1}$ (Tabela 1), que ocorre no mês de outubro. Assim, a lâmina bruta de projeto foi de $7,1 \mathrm{~mm} \mathrm{~d}^{-1}$.

Tendo em vista o objetivo do trabalho, foram testadas seis jornadas diárias de trabalho, de 8,5,

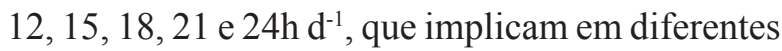
aproveitamentosde cada posto tarifário,conforme a Tabela 3. Os sistemas de irrigação resultantes dessas combinações de jornada foram dimensionados para uma área de 51 hectares, segundo os critérios apresentados em Keller e Bliesner (1990) e Tarjuello (2005). 
JORNADA DIÁRIA DE TRABALHO COMO CRITÉRIO DE DIMENSIONAMENTO ECONÔMICO PARA SISTEMAS DE...

Tabela 3. Uso do posto tarifário e vazão específica de projeto

\begin{tabular}{ccccc}
\hline $\begin{array}{c}\text { Jornada de trabalho } \\
\left(\mathrm{h} \mathrm{d}^{-1}\right)\end{array}$ & $\begin{array}{c}\text { Horário } \\
\text { de ponta } \\
(\%)\end{array}$ & $\begin{array}{c}\text { Horário } \\
\text { fora de ponta } \\
(\%)\end{array}$ & $\begin{array}{c}\text { Horário } \\
\text { reservado } \\
(\%)\end{array}$ & $\begin{array}{c}\text { Vazão } \\
\text { específica } \\
\left(\mathrm{L} \mathrm{s}^{-1} \mathrm{ha}^{-1}\right)\end{array}$ \\
\hline 8,5 & $0,00 \%$ & $0,00 \%$ & $100,00 \%$ & 1,961 \\
12 & $0,00 \%$ & $29,17 \%$ & $70,83 \%$ & 1,389 \\
15 & $0,00 \%$ & $43,33 \%$ & $56,67 \%$ & 1,111 \\
18 & $0,00 \%$ & $52,78 \%$ & $47,22 \%$ & 0,926 \\
21 & $0,00 \%$ & $40,48 \%$ & $59,52 \%$ & 0,794 \\
24 & $12,50 \%$ & $52,08 \%$ & $35,42 \%$ & 0,694 \\
\hline
\end{tabular}

Para avaliação da viabilidade econômica dos sistemas de irrigação dimensionados, foi adotado o menor custo anual total (CAT), conforme Frizzone et al. (2005) e Gomes (2009), tendo em vista que todos os sistemas seriam capazes de atender as necessidades de manejo dos cultivos. O CAT é dado pela Equação 3.

$$
\mathrm{CAT}=\mathrm{CAF}+\mathrm{CAV}
$$

em que,

CAT $=$ custo anual total do sistema de irrigação, em R\$;

CAF = custo anual fixo do sistema de irrigação, em R\$; e

$\mathrm{CAV}=$ custo anual variável do sistema de irrigação, em R\$.

Compõem o CAF a depreciação do sistema de irrigação e a remuneração do capital investido, conforme a Equação 4.

$$
\operatorname{CAF}=\frac{(V i-V f) \times i}{(1+i)^{n}-1}+\frac{V i \times\left[(1+i)^{n}-1\right]}{\sum_{\lambda=1}^{n}(1+i)^{\lambda}+1}
$$

em que,

$\mathrm{Vi}=$ Valor inicial do sistema de irrigação, em R $\$$

$\mathrm{Vf}=$ Valor final do sistema de irrigação, em R\$;

$\mathrm{i}=$ taxa anual de juros reais, decimal;

$\mathrm{n}=$ vida útil do sistema de irrigação, em anos; e

$\lambda=$ expoente polinomial.

O custo anual variável (CAV), por sua vez, é dado pela Equação 5, a seguir.

$\mathrm{CAV}=\mathrm{Vi} \times \mathrm{f}_{\mathrm{m}}+\frac{[(\mathrm{FAD}+\mathrm{FAC}+\mathrm{AJA}) \times(1-\mathrm{d})+\mathrm{BAN}]}{(1+\mathrm{i})} \times \frac{\left[(1+\mathrm{r})^{\mathrm{n}}-1\right]}{\mathrm{r} \times \mathrm{n}}$ em que,

$\mathrm{f}_{\mathrm{m}}=$ fração do valor do sistema de irrigação gasto anualmente com manutenção, decimal;

$\mathrm{FAD}=$ faturamento anual da demanda de energia contratada, em R\$;

$\mathrm{FAC}$ = faturamento anual do consumo de energia elétrica, em R\$;

AJA = ajuste anual referente ao fator de potência da instalação elétrica, em R $\$$;

$\mathrm{BAN}=$ faturamento anual das bandeiras tarifárias, em R\$;

$\mathrm{d}=$ desconto sobre as tarifas aplicável ao subgrupo A rural (10\%), decimal;

$\mathrm{i}=$ alíquota dos tributos (ICMS $=12 \%, \mathrm{PIS} /$ PASEP $=1,65 \%$, COFINS $=7,60 \%$ ), decimal; e $r=$ taxa de reajuste anual da energia ${ }^{1}$, decimal;

Em relação ao CAV, o primeiro termo refere-se ao custo anual de manutenção do equipamento, aqui estimado como $5 \%$, em média, do valor inicial do equipamento (FRIZZONE et al., 2005). Os demais termos referem-se ao custo anual de bombeamento de água, dependente do subgrupo tarifário na qual o equipamento de irrigação está enquadrado. $\mathrm{O}$ último termo refere-se à bandeira tarifária vigente, um acréscimo no valor do consumo de energia, conforme a seguir:

$\mathrm{BAN}=\sum_{\mathrm{m}=1}^{12} \mathrm{C}_{\mathrm{m}} \times \mathrm{TB}_{\mathrm{m}}$

em que,

$\mathrm{m}=$ número de meses, adimensional;

$\mathrm{C}_{\mathrm{m}}=$ consumo total mensal de energia, em $\mathrm{kWh}$; $\mathrm{TB}_{\mathrm{m}}=$ tarifa referente à bandeira tarifária vigente(Tabela 4) no mês $m$, em $\mathrm{R} \$ \mathrm{kWh}^{-1}$.

1 - Foi considerado um valor de $4,5 \%$ a.a., baseado na meta de inflação do Índice de Preços ao Consumidor Amplo - IPCA. 
A Tabela 5 apresenta as tarifas para cada componente do custo de energia de acordo com o subgrupo tarifário, de acordo com CELG (2017). $\mathrm{O}$ desconto para irrigação noturnanesse subgrupo é $80 \%$ para a Região Centro-Oeste.Quando a potência requerida pelos motores elétricos puder ser atendida por um transformador de $112,5 \mathrm{kVA}$ ou inferior, ainda existe a possibilidade de faturamento com aplicação da tarifa do grupo B, cujas tarifas também estão contidas na Tabela 4, sendo que o desconto para irrigação noturna passa a ser de 67\% (ANEEL, 2010).

$O$ faturamento da demanda (FAD) para os subgrupos A3a rural convencional, A3a rural horossazonal azul e A3a rural horossazonal verde é dado pela Equação 7. Não há FAD para o subgrupo B2 rural.

O faturamento anual do consumo (FAC) para os subgrupos B2 rural, A3a rural convencional, A3a rural horossazonal azul e A3a rural horossazonal verde é dado a seguir.

Quando o fator de potência $(\cos \varphi)$ for menor que 0,92 (ANEEL, 2010), haverá incidência do ajuste anual do fator de potência (AJA). Para os subgrupos A3a rural convencional, A3a rural horossazonal azul e A3a rural horossazonal verde é dado pela Equação 9. Não há AJA para o subgrupo B2 rural.

A estimativa do consumo mensal de energia foi obtida pelo produto entre a potência do pivô central, em kW, e o tempo de operação do equipamento em cada mês, em horas. Esse tempo foi variável em cada mês, como resultado do balanço hídrico simplificado para um ciclo de um ano, levando-se em conta, dentre as culturas selecionadas na Tabela 2, o período usual de cultivo na região de FormosaGO.

Tabela 4. Bandeiras Tarifárias (ANEEL, 2013)

\begin{tabular}{lcc}
\hline & Bandeira & Tarifa $\left(\mathrm{R} \$ \mathrm{kWh}^{-1}\right)$ \\
\hline Verde & 0,000 \\
Amarela & 0,020 \\
Vermelha patamar 1 & 0,030 \\
Vermelha patamar 2 & 0,035 \\
\hline
\end{tabular}

Tabela 5. Tarifas para os diferentes subgrupos tarifários

\begin{tabular}{lcccccc}
\hline \multirow{2}{*}{ Subgrupo } & \multicolumn{3}{c}{ Demanda $\left(\mathrm{R} \$ \mathrm{~kW}^{-1}\right)$} & \multicolumn{2}{c}{ Consumo $\left(\mathrm{R} \$ \mathrm{kWh}^{-1}\right)$} \\
\cline { 2 - 7 } & Ponta & $\begin{array}{c}\text { Fora de } \\
\text { Ponta }\end{array}$ & Reativa & Ponta & $\begin{array}{c}\text { Fora de } \\
\text { Ponta }\end{array}$ & Reativo \\
\hline B2 rural & - & - & - & - & 0,29411 & - \\
\hline A3a rural convencional & - & 32,22 & 13,57 & - & 0,27366 & 0,27078 \\
\hline A3a rural azul & 34,64 & 13,57 & 13,57 & 0,44063 & 0,29513 & 0,27078 \\
\hline A3a rural verde & - & 13,57 & 13,57 & 1,28093 & 0,29513 & 0,27078 \\
\hline
\end{tabular}

$\mathrm{FAD}=\left(\sum_{\mathrm{m}=1}^{12} \mathrm{D}_{\mathrm{HPm}} \times \mathrm{TD}_{\mathrm{HP}}+\mathrm{D}_{\mathrm{HFPm}} \times \mathrm{TD}_{\mathrm{HFP}}\right)+0,10 \times \mathrm{n} \times \mathrm{D}_{\text {máx }} \times \mathrm{TD}_{\mathrm{HFP}}$

em que,

$\mathrm{m}=$ número de meses, adimensional;

$\mathrm{D}_{\mathrm{HPm}}=$ demanda de potência elétrica no horário de ponta medida no mês, em kW;

$\mathrm{TD}_{\mathrm{HP}}=$ tarifa de demanda no horário de ponta, em $\mathrm{R} \$ \mathrm{~kW}^{-1}$;

$\mathrm{D}_{\mathrm{HFPm}}=$ demanda de potência elétrica no horário fora de ponta medida no mês, em $\mathrm{kW}$;

$\mathrm{TD}_{\mathrm{HFP}}=$ tarifa de demanda no horário fora de ponta, em $\mathrm{R} \$ \mathrm{~kW}^{-1}$;

$\mathrm{D}_{\text {máx }}=$ maior demanda nos últimos 11 meses, em kW; e

$\mathrm{n}=$ número de meses completos em que o pivô fica desligado, adimensional. 
$\mathrm{FAC}=\sum_{\mathrm{m}=1}^{12} \mathrm{C}_{\mathrm{HPm}} \times \mathrm{TC}_{\mathrm{HP}}+\left[\mathrm{C}_{\mathrm{HFPm}}+\mathrm{C}_{\mathrm{HRm}} \times(1-\mathrm{f})\right] \times \mathrm{TC}_{\mathrm{HFP}}$

em que,

$\mathrm{C}_{\mathrm{HPm}}=$ consumo de energia no horário de ponta no mês, em $\mathrm{kW}^{-1} \mathrm{~h}^{-1}$;

$\mathrm{TC}_{\mathrm{HP}}=$ tarifa de consumo no horário de ponta, em $\mathrm{R} \$ \mathrm{~kW}^{-1} \mathrm{~h}^{-1}$;

$\mathrm{C}_{\mathrm{HFPm}}=$ consumo de energia no horário fora de ponta no mês, em $\mathrm{kW}^{-1} \mathrm{~h}^{-1}$;

$\mathrm{C}_{\mathrm{HRm}}=$ consumo de energia no horário reservado no mês, em $\mathrm{kW}^{-1} \mathrm{~h}^{-1}$;

$\mathrm{f}=$ desconto sobre a tarifa de consumo de energia para irrigação em horário reservado, decimal; e

$\mathrm{TC}_{\mathrm{HFP}}=$ tarifa de consumo no horário fora de ponta, em $\mathrm{R} \$ \mathrm{~kW}^{-1} \mathrm{~h}^{-1}$.

$$
\sum_{\mathrm{m}=1}^{12}\left[\left(\mathrm{D}_{\mathrm{HPm}}+\mathrm{D}_{\mathrm{HFPm}}\right) \times \mathrm{TD}_{\mathrm{r}}+\left(\mathrm{C}_{\mathrm{HPm}}+\mathrm{C}_{\mathrm{HFPm}}+\mathrm{C}_{\mathrm{HRm}}\right) \times \mathrm{TC}_{\mathrm{r}}\right] \times\left(\frac{0,92}{\cos \varphi}-1\right)
$$

em que,

$\mathrm{TD}_{\mathrm{r}}=$ tarifa de demanda reativa, em $\mathrm{R} \$ \mathrm{~kW}^{-1}$;

$\mathrm{TC}_{\mathrm{r}}=$ tarifa de consumo reativo, em $\mathrm{R} \$ \mathrm{~kW}^{-1} ; \mathrm{e}$

$\cos \varphi=$ fator de potência, adimensional.

Para comparação dos equipamentos frente às jornadas de trabalho avaliadas e diferentes possibilidades de enquadramento tarifário, foi utilizado o custo unitário de energia e o custo unitário total. O custo unitário de energia consistiu na relação entre os custos referentes apenas ao consumo anual de energia em relação ao volume ou à lâmina de água aplicada no período de um ano. O custo unitário total levou em conta, além dos custos referentes ao consumo anual de energia, todos os demais custos fixos e variáveis totais anuais envolvidos no projeto em relação ao volume (ou lâmina) de água aplicado no mesmo período.

\section{RESULTADOS E DISCUSSÃO}

A Figura 1 apresenta a distribuição e ocupação da área irrigada com as culturas selecionadas, a partir da qual foi determinado o balanço hídrico simplificado quinzenal, apresentado o seu resumo mensal na Tabela 6. Para obtenção da chuva com $50 \%$ de probabilidade de ser superada, foi usado o software educacional Irriplus, disponível para download no site: http://www.irriplus.com.br/.

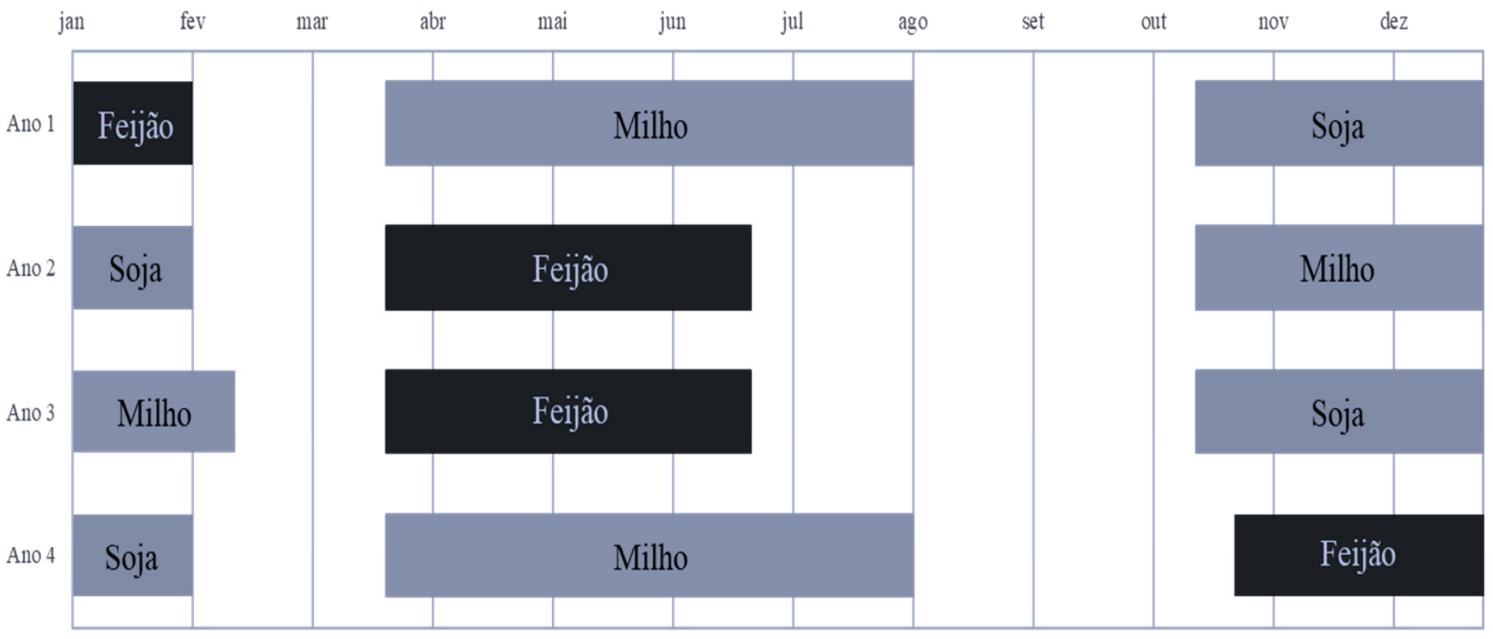

Figura 1. Ocupação temporal da área irrigada para as culturas do feijão, milho e soja no município de Formosa- GO. 
Considerando a eficiência de irrigação do sistema $(85 \%)$, ao todo deverá ser aplicada uma lâmina bruta de $555,1 \mathrm{~mm} \mathrm{ano}{ }^{-1}$ para suprir o déficit anual (Tabela 6). Foram dimensionados, para cada jornada de trabalho, dois equipamentos, um com linha lateral de diâmetro de 8 " e 6 5/8", respectivamente. As características dos sistemas de irrigação dimensionados para a área de 51 ha encontramse descritas nas Tabelas 7 e 8 .

Tabela 6. Balanço hídrico simplificado quinzenal

\begin{tabular}{ccccccccccccc}
\hline Meses & JAN & FEV & MAR & ABR & MAI & JUN & JUL & AGO & SET & OUT & NOV & DEZ \\
\hline $\begin{array}{c}\text { ETc } \\
(\mathrm{mm})\end{array}$ & 143,3 & 54,0 & 56,0 & 93,0 & 110,8 & 117,0 & 103,2 & 0,0 & 0,0 & 92,4 & 138,0 & 167,5 \\
$\begin{array}{c}\text { Chuva } \\
(\mathrm{mm})\end{array}$ & 91,6 & 116,4 & 102,3 & 57,0 & 3,2 & 0,0 & 0,0 & 0,0 & 19,5 & 88,7 & 113,2 & 182,2 \\
$\begin{array}{c}\text { Saldo } \\
(\mathrm{mm})\end{array}$ & $-51,7$ & 62,4 & 46,3 & -36 & $-107,6$ & -117 & $-103,2$ & 0 & 19,5 & $-3,7$ & $-24,8$ & 14,7 \\
\hline
\end{tabular}

* ETc - Evapotranspiração da cultura.

Tabela 7. Características dos sistemas de irrigação por pivô central de $65 / 8$ "

\begin{tabular}{|c|c|c|c|c|c|c|}
\hline \multirow{2}{*}{ Parâmetros } & \multicolumn{6}{|c|}{ Jornada $\left(\mathrm{h} \mathrm{d}^{-1}\right)$} \\
\hline & 8,5 & 12,0 & 15,0 & 18,0 & 21,0 & 24,0 \\
\hline Vazão $\left(\mathrm{m}^{3} \mathrm{~h}^{-1}\right)$ & 426,00 & 301,75 & 241,40 & 201,17 & 172,43 & 150,88 \\
\hline Vazão específica $\left(\mathrm{Ls}^{-1} \mathrm{ha}^{-1}\right)$ & 2,320 & 1,644 & 1,315 & 1,096 & 0,939 & 0,822 \\
\hline Comprimento lateral (m) & 402,91 & 402,91 & 402,91 & 402,91 & 402,91 & 402,91 \\
\hline Desnível na lateral (m) & 8,06 & 8,06 & 8,06 & 8,06 & 8,06 & 8,06 \\
\hline Diâmetro lateral & $65 / 8 ”$ & $65 / 8 ”$ & $65 / 8 ”$ & $65 / 8 ”$ & $65 / 8 ”$ & $65 / 8^{\prime \prime}$ \\
\hline Adutora & $\begin{array}{l}\text { DN300 } \\
\text { PN60 }\end{array}$ & $\begin{array}{l}\text { DN250 } \\
\text { PN60 }\end{array}$ & $\begin{array}{c}\text { DN200 PN } \\
60\end{array}$ & $\begin{array}{l}\text { DN200 } \\
\text { PN60 }\end{array}$ & $\begin{array}{l}\text { DN200 } \\
\text { PN60 }\end{array}$ & $\begin{array}{c}\text { DN200 } \\
\text { PN60 }\end{array}$ \\
\hline Comprimento da adutora (m) & 452,91 & 452,91 & 452,91 & 452,91 & 452,91 & 452,91 \\
\hline Desnível na adutora (m) & 9,06 & 9,06 & 9,06 & 9,06 & 9,06 & 9,06 \\
\hline Sucção & $\begin{array}{c}\text { DN350 } \\
\text { PN60 }\end{array}$ & $\begin{array}{c}\text { DN250 } \\
\text { PN60 }\end{array}$ & $\begin{array}{r}\text { DN250 } \\
\text { PN60 }\end{array}$ & $\begin{array}{c}\text { DN200 } \\
\text { PN60 }\end{array}$ & $\begin{array}{c}\text { DN200 } \\
\text { PN60 }\end{array}$ & $\begin{array}{c}\text { DN200 } \\
\text { PN60 }\end{array}$ \\
\hline Comprimento da sucção (m) & 24,00 & 24,00 & 24,00 & 24,00 & 24,00 & 24,00 \\
\hline Desnível da sucção (m) & 2,5 & 2,5 & 2,5 & 2,5 & 2,5 & 2,5 \\
\hline Altura manométrica (mca) & 76,22 & 58,07 & 54,12 & 48,19 & 44,38 & 41,84 \\
\hline Rendimento da bomba (\%) & $82,0 \%$ & $79,6 \%$ & $78,4 \%$ & $79,6 \%$ & $79,2 \%$ & $79,8 \%$ \\
\hline Potência requerida (cv) & 146,66 & 81,53 & 61,72 & 45,11 & 35,79 & 29,3 \\
\hline Potência nominal (cv) & 150,00 & 100 & 75 & 50 & 40 & 30 \\
\hline Índice de carregamento (\%) & $97,8 \%$ & $81,5 \%$ & $82,3 \%$ & $90,2 \%$ & $89,5 \%$ & $97,7 \%$ \\
\hline Rendimento do motor (\%) & $95,2 \%$ & $94,5 \%$ & $94,3 \%$ & $93,4 \%$ & $93,3 \%$ & $93,3 \%$ \\
\hline $\cos \varphi$ & 0,86 & 0,84 & 0,85 & 0,83 & 0,83 & 0,83 \\
\hline Potência requerida $(\mathrm{kW})$ & 113,4 & 63,5 & 48,2 & 35,5 & 28,2 & 23,1 \\
\hline
\end{tabular}


Cabe destacar aqui que os motores elétricos selecionados não contemplam a folga recomendada por Azevedo Netto (2010), Bernardo et al. (2006), Carvalho et al. (2008) e Denículi (2005), uma vez que os motores já possuem um fator de serviço de 1,15 , isto é, por si só já contemplam uma reserva de $15 \%$ da potência nominal. Este procedimento foi adotado a fim de se evitar a ociosidade de carga do equipamento e, consequentemente, sua baixa eficiência, conforme Oliveira Filho et al. (2010).
Esses autores recomendam que não seja utilizado acréscimo na potência no dimensionamento de motores com fator de serviço maior do que a unidade para acionamento de bomba hidráulica.

As Tabelas 9, 10, 11 e 12 apresentam os resultados dos custos dos pivôs com laterais de 6 5/8" em cada jornada de trabalho, para os subgrupos B2 rural, A3a rural convencional, A3a rural azul e A3a rural verde, respectivamente.

Tabela 8. Características dos sistemas de irrigação por pivô central de 8"

\begin{tabular}{|c|c|c|c|c|c|c|}
\hline \multirow{2}{*}{ Parâmetros } & \multicolumn{6}{|c|}{ Jornada $\left(\mathrm{h} \mathrm{d}^{-1}\right)$} \\
\hline & 8,5 & 12,0 & 15,0 & 18,0 & 21,0 & 24,0 \\
\hline Vazão $\left(\mathrm{m}^{3} \mathrm{~h}^{-1}\right)$ & 426,00 & 301,75 & 241,40 & 201,17 & 172,43 & 150,88 \\
\hline Vazão específica $\left(\mathrm{Ls}^{-1} \mathrm{ha}^{-1}\right)$ & 2,320 & 1,644 & 1,315 & 1,096 & 0,939 & 0,822 \\
\hline Comprimento lateral (m) & 402,91 & 402,91 & 402,91 & 402,91 & 402,91 & 402,91 \\
\hline Desnível na lateral & 8,06 & 8,06 & 8,06 & 8,06 & 8,06 & 8,06 \\
\hline Diâmetro lateral & $8 "$ & $8 ”$ & $8 "$ & $8 "$ & $8 "$ & $8 "$ \\
\hline Adutora & DN300 PN80 & DN250 PN60 & DN200 PN 60 & DN200 PN60 & DN200 PN60 & DN200 PN60 \\
\hline Comprimento da adutora (m) & 452,91 & 452,91 & 452,91 & 452,91 & 452,91 & 452,91 \\
\hline Desnível na adutora (m) & 9,06 & 9,06 & 9,06 & 9,06 & 9,06 & 9,06 \\
\hline Sucção & DN350 PN80 & DN250 PN60 & DN250 PN60 & DN200 PN60 & DN200 PN60 & DN200 PN60 \\
\hline Comprimento da sucção (m) & 24,00 & 24,00 & 24,00 & 24,00 & 24,00 & 24,00 \\
\hline Desnível da sucção (m) & 2,5 & 2,5 & 2,5 & 2,5 & 2,5 & 2,5 \\
\hline Altura manométrica (mca) & 51,27 & 44,96 & 45,44 & 42,01 & 39,72 & 38,21 \\
\hline Rendimento da bomba (\%) & $80,9 \%$ & $82,6 \%$ & $81,2 \%$ & $79,7 \%$ & $78,4 \%$ & $79,8 \%$ \\
\hline Potência requerida (cv) & 99,99 & 60,83 & 50,03 & 39,27 & 32,36 & 26,76 \\
\hline Potência comercial (cv) & 100,00 & 60 & 50 & 40 & 40 & 30 \\
\hline Índice de carregamento (\%) & $100,0 \%$ & $101,4 \%$ & $100,1 \%$ & $98,2 \%$ & $80,9 \%$ & $89,2 \%$ \\
\hline Rendimento do motor (\%) & $94,6 \%$ & $94,1 \%$ & $93,6 \%$ & $93,5 \%$ & $92,8 \%$ & $93,3 \%$ \\
\hline $\cos \varphi$ & 0,87 & 0,86 & 0,85 & 0,84 & 0,84 & 0,83 \\
\hline Potência requerida $(\mathrm{kW})$ & 77,8 & 47,6 & 39,3 & 30,9 & 25,7 & 21,1 \\
\hline
\end{tabular}

Tabela 9. Custos dos pivôs centrais de 6 5/8" no subgrupo B2 rural

\begin{tabular}{|c|c|c|c|c|c|c|}
\hline \multirow{2}{*}{ Parâmetros } & \multicolumn{6}{|c|}{ Jornada $\left(\mathrm{h} \mathrm{d}^{-1}\right)$} \\
\hline & 8,5 & 12,0 & 15,0 & 18,0 & 21,0 & 24,0 \\
\hline Valor inicial (R\$) & 323.687 & 289.599 & 274.752 & 270.103 & 270.419 & 267.735 \\
\hline Valor inicial $\left(\mathrm{R} \$ \mathrm{ha}^{-1}\right)$ & 6.347 & 5.678 & 5.387 & 5.296 & 5.302 & 5.250 \\
\hline Custo de energia $\left(\mathrm{R} \$ \mathrm{ano}^{-1}\right)$ & 11.373 & 12.208 & 13.067 & 12.422 & 12.091 & 11.725 \\
\hline Custo de manutenção $\left(\mathrm{R} \$ a n o^{-1}\right)$ & 1.079 & 965 & 916 & 900 & 901 & 892 \\
\hline Custo Anual Fixo $\left(\mathrm{R} \$ \mathrm{ano}^{-1}\right)$ & 30.124 & 26.952 & 25.570 & 25.137 & 25.167 & 24.917 \\
\hline Custo Anual Variável $\left(\mathrm{R} \$ a n o^{-1}\right)$ & 12.452 & 13.174 & 13.983 & 13.322 & 12.992 & 12.618 \\
\hline Custo Anual Total (R\$) & 42.576 & 40.125 & 39.552 & 38.460 & 38.159 & 37.535 \\
\hline Custo unitário de energia $\left(\mathrm{R} \$ \mathrm{~m}^{-3} \mathrm{ano}^{-1}\right)$ & 0,040 & 0,043 & 0,046 & 0,044 & 0,043 & 0,041 \\
\hline Custo unitário de energia $\left(\mathrm{R} \$ \mathrm{~mm}^{-1} \mathrm{ha}^{-1} \mathrm{ano}^{-1}\right)$ & 0,402 & 0,431 & 0,462 & 0,439 & 0,427 & 0,414 \\
\hline 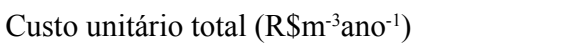 & 0,150 & 0,142 & 0,140 & 0,136 & 0,135 & 0,133 \\
\hline Custo unitário total $\left(\mathrm{R} \$ \mathrm{~mm}^{-1} \mathrm{ha}^{-1} \mathrm{ano}^{-1}\right)$ & 1,504 & 1,417 & 1,397 & 1,359 & 1,348 & 1,326 \\
\hline
\end{tabular}


LEITE, C. V. et al.

Tabela 10. Custos dos pivôs centrais de 6 5/8" no subgrupo A3a rural convencional

\begin{tabular}{lcccccc}
\hline \multirow{2}{*}{ Parâmetros } & \multicolumn{7}{c}{ Jornada $\left(\mathrm{h} \mathrm{d}^{-1}\right)$} \\
\cline { 2 - 7 } & 8,5 & 12,0 & 15,0 & 18,0 & 21,0 & 24,0 \\
\hline Valor inicial $(\mathrm{R} \$)$ & 323.687 & 289.599 & 274.752 & 270.103 & 270.419 & 267.735 \\
Valor inicial $\left(\mathrm{R} \$ \mathrm{ha}^{-1}\right)$ & 6.347 & 5.678 & 5.387 & 5.296 & 5.302 & 5.250 \\
Custo de energia $\left(\mathrm{R} \$ \mathrm{ano}^{-1}\right)$ & 41.170 & 29.580 & 26.115 & 22.567 & 20.253 & 24.899 \\
Custo de manutenção $\left(\mathrm{R} \$ \mathrm{ano}^{-1}\right)$ & 1.079 & 965 & 916 & 900 & 901 & 892 \\
Custo Anual Fixo $\left(\mathrm{R} \$ \mathrm{ano}^{-1}\right)$ & 30.124 & 26.952 & 25.570 & 25.137 & 25.167 & 24.917 \\
Custo Anual Variável $\left(\mathrm{R} \$ \mathrm{ano}^{-1}\right)$ & 42.249 & 30.545 & 27.031 & 23.468 & 21.154 & 25.791 \\
Custo Anual Total $(\mathrm{R} \$)$ & 72.373 & 57.497 & 52.601 & 48.605 & 46.321 & 50.708 \\
Custo unitário de energia $\left(\mathrm{R} \$ \mathrm{~m}^{-3} \mathrm{ano}^{-1}\right)$ & 0,145 & 0,104 & 0,092 & 0,080 & 0,072 & 0,088 \\
Custo unitário de energia $\left(\mathrm{R} \$ \mathrm{~mm}^{-1} \mathrm{ha}^{-1} \mathrm{ano}^{-1}\right)$ & 1,454 & 1,045 & 0,922 & 0,797 & 0,715 & 0,880 \\
Custo unitário total $\left(\mathrm{R} \$ \mathrm{~m}^{-3} \mathrm{ano}^{-1}\right)$ & 0,256 & 0,203 & 0,186 & 0,172 & 0,164 & 0,179 \\
Custo unitário total $\left(\mathrm{R} \$ \mathrm{~mm}^{-1} \mathrm{ha}^{-1} \mathrm{ano}^{-1}\right)$ & 2,556 & 2,031 & 1,858 & 1,717 & 1,636 & 1,791 \\
\hline
\end{tabular}

Tabela 11. Custos dos pivôs centrais de 6 5/8" no subgrupo A3a rural azul

\begin{tabular}{lcccccc}
\hline \multirow{2}{*}{\multicolumn{1}{c}{ Parâmetros }} & \multicolumn{7}{c}{ Jornada $\left(\mathrm{h} \mathrm{d}^{-1}\right)$} \\
\cline { 2 - 7 } & 8,5 & 12,0 & 15,0 & 18,0 & 21,0 & 24,0 \\
\hline Valor inicial $(\mathrm{R} \$)$ & 323.687 & 289.599 & 274.752 & 270.103 & 270.419 & 267.735 \\
Valor inicial $\left(\mathrm{R} \$ \mathrm{ha}^{-1}\right)$ & 6.347 & 5.678 & 5.387 & 5.296 & 5.302 & 5.250 \\
Custo de energia $\left(\mathrm{R} \$ \mathrm{ano}^{-1}\right)$ & 23.231 & 19.830 & 18.964 & 17.484 & 16.361 & 23.102 \\
Custo de manutenção $\left(\mathrm{R} \$ \mathrm{ano}^{-1}\right)$ & 1.079 & 965 & 916 & 900 & 901 & 892 \\
Custo Anual Fixo $\left(\mathrm{R} \$ \mathrm{ano}^{-1}\right)$ & 30.124 & 26.952 & 25.570 & 25.137 & 25.167 & 24.917 \\
Custo Anual Variável $\left(\mathrm{R} \$ \mathrm{ano}^{-1}\right)$ & 24.310 & 20.795 & 19.880 & 18.385 & 17.263 & 23.994 \\
Custo Anual Total $(\mathrm{R} \$)$ & 54.434 & 47.747 & 45.450 & 43.522 & 42.429 & 48.911 \\
Custo unitário de energia $\left(\mathrm{R} \$ \mathrm{~m}^{-3} \mathrm{ano}^{-1}\right)$ & 0,082 & 0,070 & 0,067 & 0,062 & 0,058 & 0,082 \\
Custo unitário de energia $\left(\mathrm{R} \$ \mathrm{~mm}^{-1} \mathrm{ha}^{-1} \mathrm{ano}^{-1}\right)$ & 0,821 & 0,700 & 0,670 & 0,618 & 0,578 & 0,816 \\
Custo unitário total $\left(\mathrm{R} \$ \mathrm{~m}^{-3} \mathrm{ano}^{-1}\right)$ & 0,192 & 0,169 & 0,161 & 0,154 & 0,150 & 0,173 \\
Custo unitário total $\left(\mathrm{R} \$ \mathrm{~mm}^{-1} \mathrm{ha}^{-1} \mathrm{ano}^{-1}\right)$ & 1,923 & 1,687 & 1,605 & 1,537 & 1,499 & 1,728 \\
\hline
\end{tabular}

Tabela 12. Custos dos pivôs centrais de 6 5/8" no subgrupo A3a rural verde

\begin{tabular}{lcccccc}
\hline \multirow{2}{*}{ Parâmetros } & \multicolumn{7}{c}{ Jornada $\left(\mathrm{h} \mathrm{d}^{-1}\right)$} \\
\cline { 2 - 7 } & 8,5 & 12,0 & 15,0 & 18,0 & 21,0 & 24,0 \\
\hline Valor inicial $(\mathrm{R} \$)$ & 323.687 & 289.599 & 274.752 & 270.103 & 270.419 & 267.735 \\
Valor inicial $\left(\mathrm{R} \$ \mathrm{ha}^{-1}\right)$ & 6.347 & 5.678 & 5.387 & 5.296 & 5.302 & 5.250 \\
Custo de energia $\left(\mathrm{R} \$ \mathrm{ano}^{-1}\right)$ & 23.231 & 19.919 & 19.031 & 17.534 & 16.400 & 23.812 \\
Custo de manutenção $\left(\mathrm{R} \$ \mathrm{ano}^{-1}\right)$ & 1.079 & 965 & 916 & 900 & 901 & 892 \\
Custo Anual Fixo $\left(\mathrm{R} \$ \mathrm{ano}^{-1}\right)$ & 30.124 & 26.952 & 25.570 & 25.137 & 25.167 & 24.917 \\
Custo Anual Variável $\left(\mathrm{R} \$ \mathrm{ano}^{-1}\right)$ & 24.310 & 20.884 & 19.947 & 18.434 & 17.302 & 24.704 \\
Custo Anual Total $(\mathrm{R} \$)$ & 54.434 & 47.836 & 45.517 & 43.572 & 42.469 & 49.621 \\
Custo unitário de energia $\left(\mathrm{R} \$ \mathrm{~m}^{-3} \mathrm{ano}^{-1}\right)$ & 0,082 & 0,070 & 0,067 & 0,062 & 0,058 & 0,084 \\
Custo unitário de energia $\left(\mathrm{R} \$ \mathrm{~mm}^{-1} \mathrm{ha}^{-1} \mathrm{ano}^{-1}\right)$ & 0,821 & 0,704 & 0,672 & 0,619 & 0,579 & 0,841 \\
Custo unitário total $\left(\mathrm{R} \$ \mathrm{~m}^{-3} \mathrm{ano}^{-1}\right)$ & 0,192 & 0,169 & 0,161 & 0,154 & 0,150 & 0,175 \\
Custo unitário total $\left(\mathrm{R} \$ \mathrm{~mm}^{-1} \mathrm{ha}^{-1} \mathrm{ano}^{-1}\right)$ & 1,923 & 1,690 & 1,608 & 1,539 & 1,500 & 1,753 \\
\hline
\end{tabular}


JORNADA DIÁRIA DE TRABALHO COMO CRITÉRIO DE DIMENSIONAMENTO ECONÔMICO PARA SISTEMAS DE...

As Figuras 2 e 3 mostram a composição do custo anual total por unidade de área para os pivôs com laterais de $65 / 8$ ". Foi adotada a bandeira tarifária do pior cenário, qual seja, a bandeira vermelha patamar 2, que acrescentou $\mathrm{R} \$ 0,035$ $\mathrm{kWh}^{-1}$.

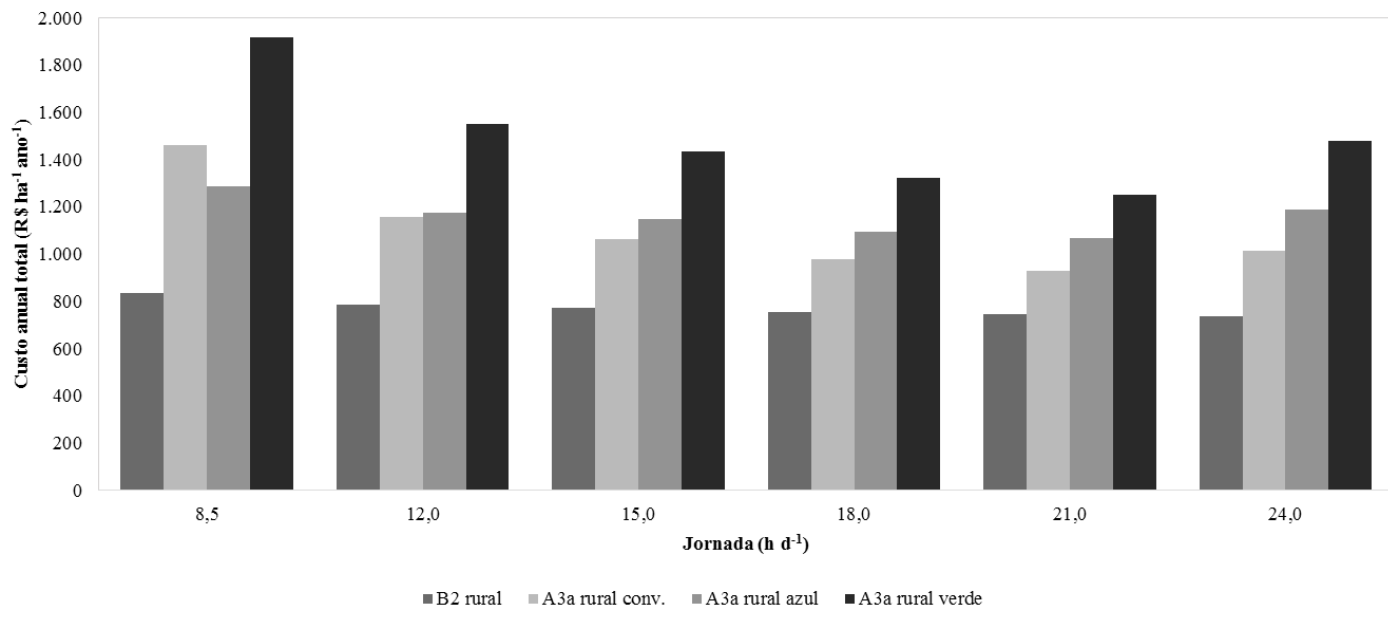

Figura 2. Custo anual total por hectare para os pivôs centrais de $65 / 8$ "

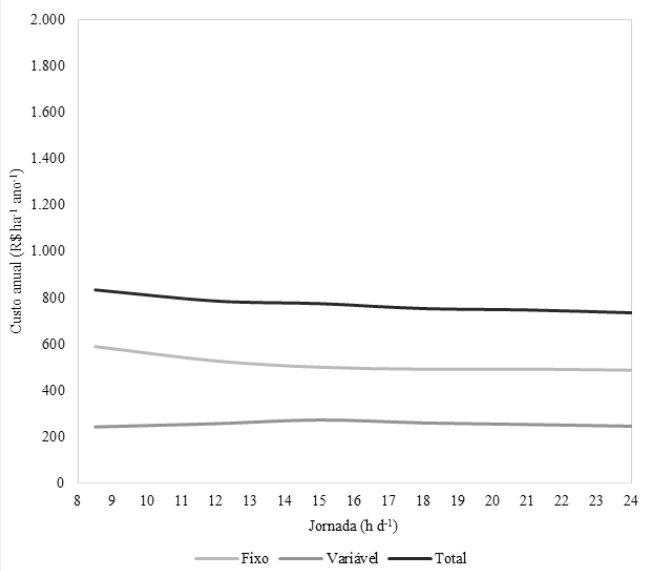

(a)

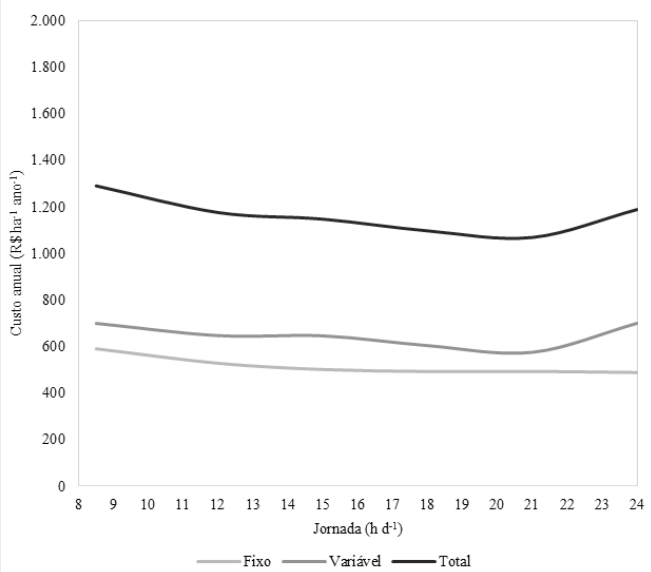

(c)



(b)



(d)

Figura 3. Composição de custos para os pivôs de 6 5/8" nos subgrupos B3 rural (a), A3a rural convencional (b), A3a rural azul (c) e A3a rural verde (d) 
O menor custo total para o pivô de $65 / 8$ " foi de $\mathrm{R} \$ 735,97 \mathrm{ha}^{-1}$ ano $^{-1}$, no subgrupo B2 rural para a jornada de $24 \mathrm{~h} \mathrm{~d}^{-1}$ (Figuras 2 e 3a), obtendo um custo unitário de $\mathrm{R} \$ 1,326 \mathrm{~mm}^{-1} \mathrm{ha}^{-1} \mathrm{ano}^{-1}$ (Tabela 9). O custo de energia representa $31,2 \%$ desse valor. Já para os subgrupos A3a rural convencional, azul e verde (Figuras $3 b, 3 c$ e $3 d$, respectivamente), os menores custos totais para o pivô de $65 / 8$ " foram de $\mathrm{R} \$ 930,93$ ha $^{-1} \mathrm{ano}^{-1}$, R $\$ 1.069,02$ ha $^{-1}$ ano $^{-1} \mathrm{e}$
$\mathrm{R} \$ 1.252,50 \mathrm{ha}^{-1} \mathrm{ano}^{-1}$, respectivamente, todos obtidos para a jornada de $21 \mathrm{~h} \mathrm{~d}^{-1}$. Os custos unitários (Tabelas 10, 11 e 12) foram $\mathrm{R} \$ 1,636 \mathrm{~mm}^{-1} \mathrm{ha}^{-1} \mathrm{ano}^{-1}$, $\mathrm{R} \$ 1,499 \mathrm{~mm}^{-1} \mathrm{ha}^{-1}$ ano $^{-1}$ e R $\$ 1,500 \mathrm{~mm}^{-1} \mathrm{ha}^{-1}$ ano $^{-}$ ${ }^{1}$. A energia representou $43,7 \%, 38,6 \%$ e $38,6 \%$, respectivamente.

As Tabelas 13, 14, 15 e 16, por sua vez, apresentam os custos dos pivôs de 8" em cada jornada de trabalho para todos os subgrupos tarifários.

Tabela 13. Custos dos sistemas dos pivôs de 8" no subgrupo B2 rural.

\begin{tabular}{lcccccc}
\hline \multirow{2}{*}{ Parâmetros } & \multicolumn{7}{c}{ Jornada $\left(\mathrm{h} \mathrm{d}^{-1}\right)$} \\
\cline { 2 - 7 } & 8,5 & 12,0 & 15,0 & 18,0 & 21,0 & 24,0 \\
\hline Valor inicial $(\mathrm{R} \$)$ & 332.452 & 309.301 & 293.470 & 290.246 & 290.562 & 283.943 \\
Valor inicial $\left(\mathrm{R} \$ \mathrm{ha}^{-1}\right)$ & 6.519 & 6.065 & 5.754 & 5.691 & 5.697 & 5.568 \\
Custo de energia $\left(\mathrm{R} \$ \mathrm{ano}^{-1}\right)$ & 7.802 & 9.151 & 10.654 & 10.812 & 11.019 & 10.710 \\
Custo de manutenção $\left(\mathrm{R} \$ \mathrm{ano}^{-1}\right)$ & 1.108 & 1.031 & 978 & 967 & 969 & 946 \\
Custo Anual Fixo $\left(\mathrm{R} \$ \mathrm{ano}^{-1}\right)$ & 30.940 & 28.785 & 27.312 & 27.012 & 27.041 & 26.425 \\
Custo Anual Variável $\left(\mathrm{R} \$ \mathrm{ano}^{-1}\right)$ & 8.911 & 10.182 & 11.632 & 11.780 & 11.987 & 11.657 \\
Custo Anual Total $(\mathrm{R} \$)$ & 39.850 & 38.968 & 38.944 & 38.792 & 39.029 & 38.082 \\
Custo unitário de energia $\left(\mathrm{R} \$ \mathrm{~m}^{-3} \mathrm{ano}^{-1}\right)$ & 0,028 & 0,032 & 0,038 & 0,038 & 0,039 & 0,038 \\
Custo unitário de energia $\left(\mathrm{R} \$ \mathrm{~mm}^{-1} \mathrm{ha}^{-1} \mathrm{ano}^{-1}\right)$ & 0,276 & 0,323 & 0,376 & 0,382 & 0,389 & 0,378 \\
Custo unitário total $\left(\mathrm{R} \$ \mathrm{~m}^{-3} \mathrm{ano}^{-1}\right)$ & 0,141 & 0,138 & 0,138 & 0,137 & 0,138 & 0,135 \\
Custo unitário total $\left(\mathrm{R} \$ \mathrm{~mm}^{-1} \mathrm{ha}^{-1} \mathrm{ano}^{-1}\right)$ & 1,408 & 1,376 & 1,376 & 1,370 & 1,379 & 1,345 \\
\hline
\end{tabular}

Tabela 14. Custos dos sistemas dos pivôs de 8" no subgrupo A3a rural convencional.

\begin{tabular}{lcccccc}
\hline \multirow{2}{*}{ Parâmetros } & \multicolumn{7}{c}{ Jornada $\left(\mathrm{h} \mathrm{d}^{-1}\right)$} \\
\cline { 2 - 7 } & 8,5 & 12,0 & 15,0 & 18,0 & 21,0 & 24,0 \\
\hline Valor inicial $(\mathrm{R} \$)$ & 332.452 & 309.301 & 293.470 & 290.246 & 290.562 & 283.943 \\
Valor inicial $\left(\mathrm{R} \$ \mathrm{ha}^{-1}\right)$ & 6.519 & 6.065 & 5.754 & 5.691 & 5.697 & 5.568 \\
Custo de energia $\left(\mathrm{R} \$ \mathrm{ano}^{-1}\right)$ & 27.961 & 21.721 & 21.293 & 19.438 & 18.264 & 22.743 \\
Custo de manutenção $\left(\mathrm{R} \$ \mathrm{ano}^{-1}\right)$ & 1.108 & 1.031 & 978 & 967 & 969 & 946 \\
Custo Anual Fixo $\left(\mathrm{R} \$ \mathrm{ano}^{-1}\right)$ & 30.940 & 28.785 & 27.312 & 27.012 & 27.041 & 26.425 \\
Custo Anual Variável $\left(\mathrm{R} \$ \mathrm{ano}^{-1}\right)$ & 29.070 & 22.752 & 22.271 & 20.405 & 19.233 & 23.690 \\
Custo Anual Total $(\mathrm{R} \$)$ & 60.009 & 51.537 & 49.583 & 47.417 & 46.274 & 50.115 \\
Custo unitário de energia $\left(\mathrm{R} \$ \mathrm{~m}^{-3} \mathrm{ano}^{-1}\right)$ & 0,099 & 0,077 & 0,075 & 0,069 & 0,065 & 0,080 \\
Custo unitário de energia $\left(\mathrm{R} \$ \mathrm{~mm}^{-1} \mathrm{ha}^{-1} \mathrm{ano}^{-1}\right)$ & 0,988 & 0,767 & 0,752 & 0,687 & 0,645 & 0,803 \\
Custo unitário total $\left(\mathrm{R} \$ \mathrm{~m}^{-3} \mathrm{ano}^{-1}\right)$ & 0,212 & 0,182 & 0,175 & 0,167 & 0,163 & 0,177 \\
Custo unitário total $\left(\mathrm{R} \$ \mathrm{~mm}^{-1} \mathrm{ha}^{-1} \mathrm{ano}^{-1}\right)$ & 2,120 & 1,820 & 1,751 & 1,675 & 1,635 & 1,770 \\
\hline
\end{tabular}


JORNADA DIÁRIA DE TRABALHO COMO CRITÉRIO DE DIMENSIONAMENTO ECONÔMICO PARA SISTEMAS DE...

Tabela 15. Custos dos sistemas dos pivôs de 8" no subgrupo A3a rural azul

\begin{tabular}{lcccccc}
\hline \multirow{2}{*}{\multicolumn{1}{c}{ Parâmetros }} & \multicolumn{7}{c}{ Jornada $\left(\mathrm{h} \mathrm{d}^{-1}\right)$} \\
\cline { 2 - 7 } & 8,5 & 12,0 & 15,0 & 18,0 & 21,0 & 24,0 \\
\hline Valor inicial $(\mathrm{R} \$)$ & 332.452 & 309.301 & 293.470 & 290.246 & 290.562 & 283.943 \\
Valor inicial $\left(\mathrm{R} \$ \mathrm{ha}^{-1}\right)$ & 6.519 & 6.065 & 5.754 & 5.691 & 5.697 & 5.568 \\
Custo de energia $\left(\mathrm{R} \$ \mathrm{ano}^{-1}\right)$ & 15.654 & 14.413 & 15.462 & 15.013 & 14.718 & 21.101 \\
Custo de manutenção $\left(\mathrm{R} \$ \mathrm{ano}^{-1}\right)$ & 1.108 & 1.031 & 978 & 967 & 969 & 946 \\
Custo Anual Fixo $\left(\mathrm{R} \$ \mathrm{ano}^{-1}\right)$ & 30.940 & 28.785 & 27.312 & 27.012 & 27.041 & 26.425 \\
Custo Anual Variável $\left(\mathrm{R} \$ \mathrm{ano}^{-1}\right)$ & 16.763 & 15.444 & 16.440 & 15.981 & 15.686 & 22.048 \\
Custo Anual Total $(\mathrm{R} \$)$ & 47.702 & 44.229 & 43.752 & 42.993 & 42.728 & 48.473 \\
Custo unitário de energia $\left(\mathrm{R} \$ \mathrm{~m}^{-3} \mathrm{ano}^{-1}\right)$ & 0,055 & 0,051 & 0,055 & 0,053 & 0,052 & 0,075 \\
Custo unitário de energia $\left(\mathrm{R} \$ \mathrm{~mm}^{-1} \mathrm{ha}^{-1} \mathrm{ano}^{-1}\right)$ & 0,553 & 0,509 & 0,546 & 0,530 & 0,520 & 0,745 \\
Custo unitário total $\left(\mathrm{R} \$ \mathrm{~m}^{-3} \mathrm{ano}^{-1}\right)$ & 0,168 & 0,156 & 0,155 & 0,152 & 0,151 & 0,171 \\
Custo unitário total $\left(\mathrm{R} \$ \mathrm{~mm}^{-1} \mathrm{ha}^{-1} \mathrm{ano}^{-1}\right)$ & 1,685 & 1,562 & 1,545 & 1,519 & 1,509 & 1,712 \\
\hline
\end{tabular}

Tabela 16. Custos dos sistemas dos pivôs de 8" no subgrupo A3a rural verde

\begin{tabular}{lcccccc}
\hline \multirow{2}{*}{\multicolumn{1}{c}{ Parâmetros }} & \multicolumn{7}{c}{ Jornada $\left(\mathrm{h} \mathrm{d}^{-1}\right)$} \\
\cline { 2 - 7 } & 8,5 & 12,0 & 15,0 & 18,0 & 21,0 & 24,0 \\
\hline Valor inicial $(\mathrm{R} \$)$ & 332.452 & 309.301 & 293.470 & 290.246 & 290.562 & 283.943 \\
Valor inicial $\left(\mathrm{R} \$ \mathrm{ha}^{-1}\right)$ & 6.519 & 6.065 & 5.754 & 5.691 & 5.697 & 5.568 \\
Custo de energia $\left(\mathrm{R} \$ \mathrm{ano}^{-1}\right)$ & 15.654 & 14.479 & 15.517 & 15.057 & 14.754 & 21.750 \\
Custo de manutenção $\left(\mathrm{R} \$ \mathrm{ano}^{-1}\right)$ & 1.108 & 1.031 & 978 & 967 & 969 & 946 \\
Custo Anual Fixo $\left(\mathrm{R} \$ \mathrm{ano}^{-1}\right)$ & 30.940 & 28.785 & 27.312 & 27.012 & 27.041 & 26.425 \\
Custo Anual Variável $\left(\mathrm{R} \$ \mathrm{ano}^{-1}\right)$ & 16.763 & 15.510 & 16.495 & 16.024 & 15.722 & 22.697 \\
Custo Anual Total $(\mathrm{R} \$)$ & 47.702 & 44.295 & 43.807 & 43.036 & 42.763 & 49.122 \\
Custo unitário de energia $\left(\mathrm{R} \$ \mathrm{~m}^{-3} \mathrm{ano}^{-1}\right)$ & 0,055 & 0,051 & 0,055 & 0,053 & 0,052 & 0,077 \\
Custo unitário de energia $\left(\mathrm{R} \$ \mathrm{~mm}^{-1} \mathrm{ha}^{-1} \mathrm{ano}^{-1}\right)$ & 0,553 & 0,511 & 0,548 & 0,532 & 0,521 & 0,768 \\
Custo unitário total $\left(\mathrm{R} \$ \mathrm{~m}^{-3} \mathrm{ano}^{-1}\right)$ & 0,168 & 0,156 & 0,155 & 0,152 & 0,151 & 0,174 \\
Custo unitário total $\left(\mathrm{R} \$ \mathrm{~mm}^{-1} \mathrm{ha}^{-1} \mathrm{ano}^{-1}\right)$ & 1,685 & 1,565 & 1,547 & 1,520 & 1,511 & 1,735 \\
\hline
\end{tabular}



Figura 4. Custo anual total por hectare para os pivôs centrais de 8" 
As Figuras 4 e 5 mostram a composição do custo anual total por unidade de área para os pivôs com laterais de 8", sendo que também foi adotada bandeira tarifária vermelha patamar 2 .

De forma semelhante ao pivô de $65 / 8$ ", o menor custo total para o pivô de 8 " foi de $\mathrm{R} \$ 746,70 \mathrm{ha}^{-1}$ $\mathrm{ano}^{-1}$, no subgrupo B2 rural para a jornada de $24 \mathrm{~h}$ $\mathrm{d}^{-1}$ (Figura $\mathrm{s} 4$ e $5 \mathrm{~b}$ ), com um custo unitário de $\mathrm{R} \$ 1,345 \mathrm{~mm}^{-1} \mathrm{ha}^{-1}$ ano $^{-1}$ (Tabela 13). O custo de energia elétrica representou $28,1 \%$ desse valor. Para os subgrupos A3a rural convencional, azul e verde (Figuras 5b, 5c e 5d, respectivamente), os menores custos totais para o pivô de 8" foram $\mathrm{R} \$ 907,34 \mathrm{ha}^{-1}$ $\mathrm{ano}^{-1}, \mathrm{R} \$ 837,80 \mathrm{ha}^{-1} \mathrm{ano}^{-1}$ e R $\$ 838,50 \mathrm{ha}^{-1}$ ano $^{-1}$,

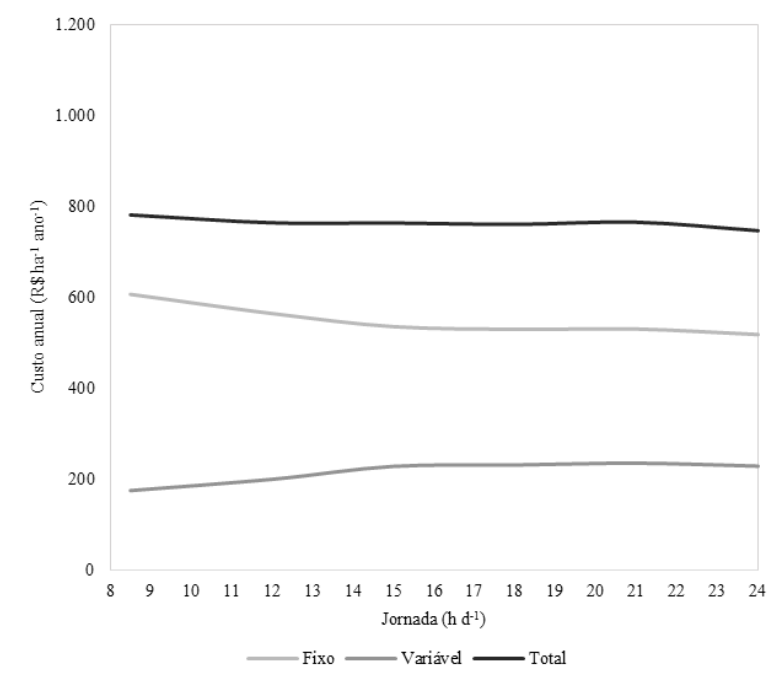

(a)

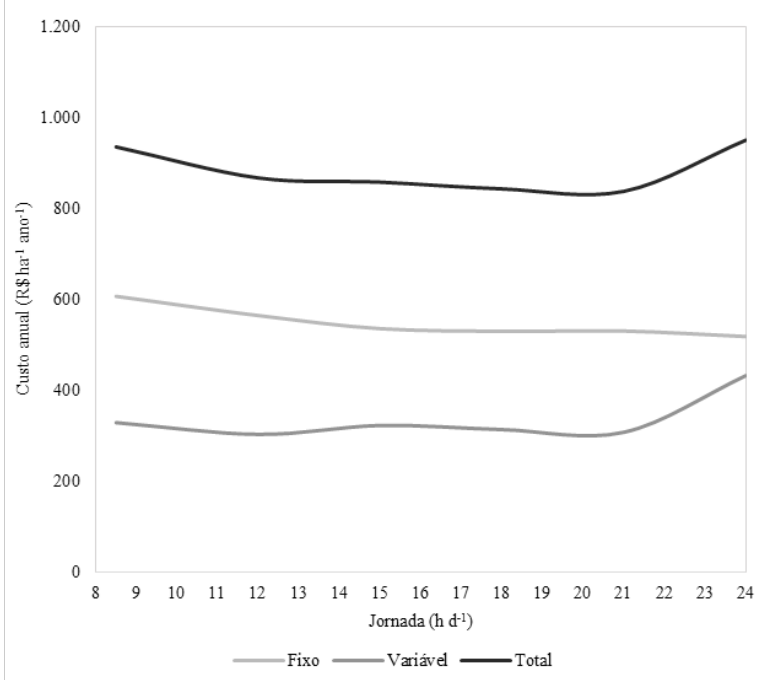

(c) respectivamente, todos obtidos para a jornada de $21 \mathrm{~h} \mathrm{~d}^{-1}$. Os custos unitários (Tabelas 14, 15 e 16) foram de R $\$ 0,645 \mathrm{~mm}^{-1} \mathrm{ha}^{-1} \mathrm{ano}^{-1}, \mathrm{R} \$ 0,520 \mathrm{~mm}^{-1}$ ha $^{-1}$ ano $^{-1}$ e R $\$ 0,521 \mathrm{~mm}^{-1}$ ha $^{-1}$ ano $^{-1}$, sendo que a energia representou $39,5 \%, 34,4 \%$ e $34,5 \%$ desses valores, respectivamente, para os subgrupos A3a rural convencional, azul e verde.

Os resultados encontrados demonstraram que, apesar da jornada de $8,5 \mathrm{~h} \mathrm{~d}^{-1}$ apresentar o menor custo de energia para o subgrupo B2 rural, isso não foi suficiente para diluir os custos de aquisição dos equipamentos, assim como o componente da demanda nos custos de energia referentes às tarifas do subgrupo A3a rural. Para estes casos, o

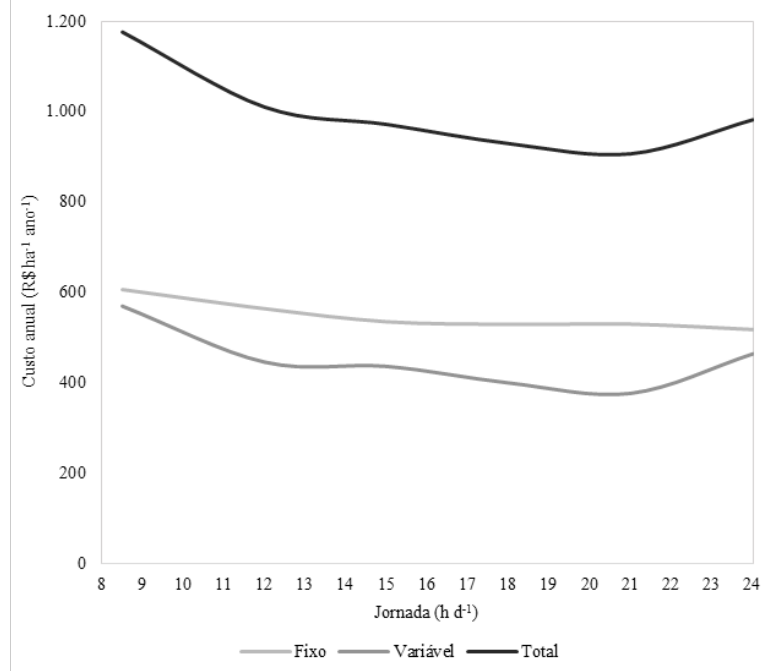

(b)

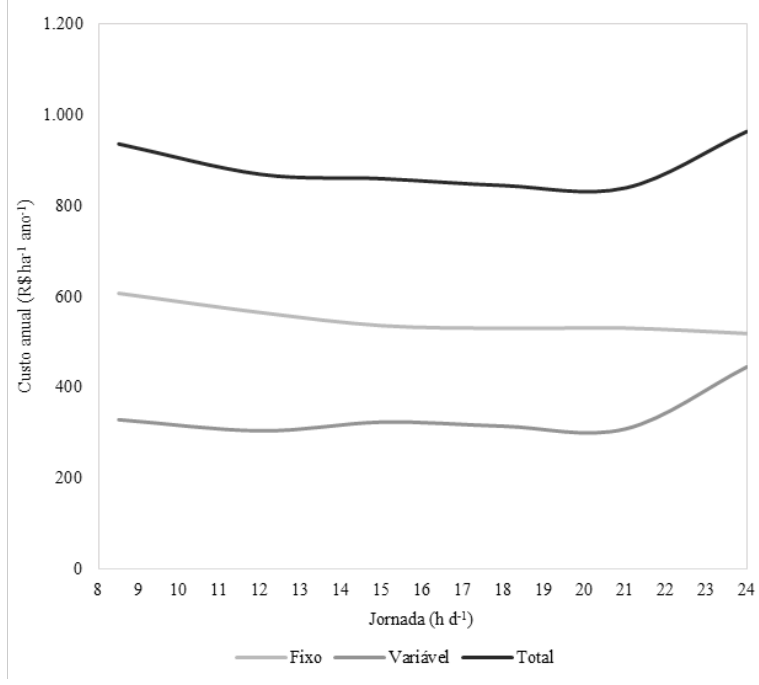

(d)

Figura 5. Composição de custos para os pivôs de 8" nos subgrupos B2 rural (a), A3a rural convencional (b), A3a rural azul (c) e A3a rural verde (d). 
menor custo anual total por hectare foi verificado para o sistema com jornada de $21 \mathrm{~h} \mathrm{~d}^{-1}$, com vazão específica de $0,939 \mathrm{~L} \mathrm{~s}^{-1} \mathrm{ha}^{-1}$, em função do melhor equilíbrio entre todos os componentes do custo, especialmente energia, devido a possibilidade de trabalharcomjornada dilatada e, consequentemente, menor vazão. Esse mesmo raciocínio, no entanto, não pode ser aplicado à jornada de $24 \mathrm{~h} \mathrm{~d}^{-1}$, uma vez que, mesmo sendo mais diluída, isto é, proporcionando menor vazão específica $(0,822 \mathrm{~L}$ $\left.\mathrm{s}^{-1} \mathrm{ha}^{-1}\right)$, as três horas adicionais ocorrem no posto tarifário mais elevado, o horário de ponta. Já no grupo B, o menor custo anual foi encontrado para a jornada de $24 \mathrm{~h} \mathrm{~d}^{-1}$, pois nesse grupo não existe o horário de ponta nem um componente de demanda no custo da energia.

Moreno et al. (2012) apontam que o aumento dos custos de energia elétrica está levando a um aumento da potência requerida pelos bombeamentos para sistemas de irrigação por pivô central na região de Albacete, Espanha. Ao buscar o dimensionamento ótimo econômico desse tipo de sistema, os autores recomendam aumentar o diâmetro das tubulações e evitar os horários de ponta, reduzindo a jornada de trabalho de $22 \mathrm{~h} \mathrm{~d}^{-1}$ para $18 \mathrm{~h} \mathrm{~d}^{-1}$ e aumentando a vazão específica usual de 1,2 a $1,3 \mathrm{~L} \mathrm{~s}^{-1} \mathrm{ha}^{-1}$ para $1,3 \mathrm{~L} \mathrm{~s}^{-1} \mathrm{ha}^{-1}$. Os autores encontraram ainda os melhores resultados econômicos para um pivô de 50ha com um diâmetro de $85 / 8$ ", o que contraria uma recomendação difundida de se usar $65 / 8$ " até $70 \mathrm{ha}$, segundo eles. Os resultados encontrados por Moreno et al. (2012) são similares aos deste estudo, quando se consideram as tarifas horossazonais.

Moraes et al. (2011), ao estudar o consumo de energia elétrica mensal em lotes a serem implantados no Projeto Público de Irrigação do município de Jaíba-MG, constatou que gastos unitários no fornecimento de água para os irrigantes podem ser minimizados pelo gerenciamento do número de horas disponíveis para irrigação, observando-se a demanda hídrica em função da época do ano e das características das culturas, para que se maximize a economia de energia elétrica.

A similaridade dos custos dos subgrupos A3a rural azul e verde se deve ao fato de que suas tarifas serem bastante semelhantes, diferindo-se apenas pelo fato de que existe uma tarifa maior de demanda no horário de ponta para a tarifa azul e uma tarifa maior de consumo no horário de ponta para a tarifa verde, conforme visto na Tabela 5.

Notou-se que, muito embora uma linha lateral de 8 " apresente maior custo do que uma de $65 / 8$ ", isso não aumentou os custos totais em função da menor potência exigida pelo conjunto moto bomba e pelo consumo de energia reduzido para o subgrupo A3a rural.

\section{CONCLUSÕES}

- O menor custo total para um pivô central de 51 ha e lâmina bruta de $7,1 \mathrm{~mm} \mathrm{~d}^{-1}$, aplicando $555,1 \mathrm{~mm} \mathrm{ano}^{-1}$ de lâmina bruta foi encontrado para linha lateral de $65 / 8$ " e jornada de trabalho de $24 \mathrm{~h} \mathrm{~d}^{-1}$ (vazão específica de $0,822 \mathrm{~L} \mathrm{~s}^{-1}$ ha$\left.{ }^{1}\right)$ no subgrupo tarifário B2 rural, no valor de $\mathrm{R} \$ 735,97 \mathrm{ha}^{-1}$ ano $^{-1}$. Para o subgrupo A3a rural, o menor custo total foi obtido para tarifa azul, de $\mathrm{R} \$ 837,80 \mathrm{ha}^{-1} \mathrm{ano}^{-1}$, com jornada de trabalho de $21 \mathrm{~h} \mathrm{~d}^{-1}$ (vazão específica de $0,939 \mathrm{~L} \mathrm{~s}^{-1} \mathrm{ha}^{-1}$ ) para linha lateral de 8 ". Isso demonstrou que uma redução da jornada de trabalho tende a não favorecer a economia, devido a importância dos custos fixos na composição do custo total para o equipamento avaliado.

\section{REFERÊNCIAS BIBLIOGRÁFICAS}

ALLEN, R.G.; PEREIRA, L.S.; RAES, D.; SMITH, M. Guidelines for computing crop water requeriments. Rome: FAO, 1998. 300p

AGÊNCIA NACIONAL DE ÁGUAS - ANA. Conjuntura dos recursos hídricos: Informe 2016. Brasília: ANA, 2016. 95 p.

AGÊNCIA NACIONAL DE ENERGIA ELÉTRICA - ANEEL. Resolução Normativa $n^{0}$ 414, de 9 de setembro de 2010. Estabelece as Condições Gerais de Fornecimento de Energia Elétrica de forma atualizada e consolidada. Brasília, 2010.

AGÊNCIA NACIONAL DE ENERGIA ELÉTRICA - ANEEL. Resolução Normativa $n^{\circ}$ 547, de 16 de abril de 2013. Estabelecer os procedimentos comerciais para aplicação do 
sistema de bandeiras tarifárias. Brasília, 2013.

ANA; EMBRAPA MILHO E SORGO. Levantamento da Agricultura Irrigada por Pivôs Centrais no Brasil - ano 2014. Disponível em: <http://www.ana.gov.br/metadados/> e $<$ http:// www.snirh.gov.br $>$. Acesso em 15/09/2017.

AZEVEDO NETTO, J. M. Manual de Hidráulica. 8 ed. São Paulo: Edgard Blucher Ltda, 1998. 670p.

BERNARDO, S; SOARES, A.A.; MANTOVANI, E. C. Manual de irrigação. 8 ed. Viçosa: Editora UFV, 2006. 625p.

BRASIL. Lei n. 10.438, de 26 de abril de 2002. Dispõe sobre a expansão da oferta de energia elétrica emergencial, recomposição tarifária extraordinária, cria o Programa de Incentivo às Fontes Alternativas de Energia Elétrica (Proinfa), a Conta de Desenvolvimento Energético (CDE), dispõe sobre a universalização do serviço público de energia elétrica, [...] e dá outras providências. Brasília, 2002.

CARVALHO, J.A.; OLIVEIRA, L.F.C. Instalações de Bombeamento para Irrigação. Lavras: Editora UFLA, 2008. 353p.

CELG DISTRIBUIÇÃO. Boletim de Tarifas Horárias 2017. Disponível em: $<$ https://www. celg.com.br/paginas/clientes/tarifa.aspx $>$. Acesso em 22/09/2017.

DENÍCULI, W. Bombas Hidráulicas. Viçosa: Editora UFV, 2005. 152p.

FRIZZONE, J.A.; ANDRADE JÚNIOR, A.S.; SOUZA, J.L.M.; ZOCOLER, J.L. Planejamento de Irrigação: Análise de Decisão de Investimento. Brasília: Embrapa Informação Tecnológica, 2005. $626 \mathrm{p}$.

GOMES, H.R. Sistemas de Bombeamento Eficiência Energética.1 ed. João Pessoa: UFPB,
Editora Universitária, 2009. 460p.

HARGREAVES, G.H.; ALLEN, R.G. History and evaluation of Hargreaves evapotranspiration equation. Journal of Irrigation and Drainage Engineering, v.129, n.1, p.53-63, 2003.

INSTITUTO NACIONAL DE METEOROLOGIA - INMET. Normais Climatológicas do Brasil 1961-1990. Ed. Revisada e Ampliada. Brasília: INMET, 2009. 465p.

KELLER, J.; BLIESNER. R.D. Sprinkle and trickle irrigation. New York: Van Nostrand Reinhold, 1990. 652p.

MANTOVANI, E.C.; BERNARDO, S.; PALARETTI, L.F. Irrigação: princípios $\mathbf{e}$ métodos. 3ed. Viçosa: UFV, Editora UFV, 2009. $355 \mathrm{p}$.

MORAES, M.J.; OLIVEIRA FILHO, D.; VIEIRA, G.H.S.; SCARCELLI, R.O.C. Gerenciamento do lado da demanda no bombeamento de água para perímetro irrigado. Revista Brasileira de Engenharia Agrícola e Ambiental, v.15, n.9, p.875-882, 2011.

MORENO, M.A.; MEDINA, D.; ORTEGA, J.F.; TARJUELO, J.M. Optimal design of center pivot systems with water supplied from wells. Agricultural Water Management, v.107, p.112121, 2012. DOI: <https://doi.org/10.1016/j. agwat.2012.01.016>

OLIVEIRA FILHO, D.; RIBEIRO, M.C.; MANTOVANI, E.C.; SOARES, A.A.; FERNANDES, H.C. Dimensionamento de motores para o bombeamento de água. Engenharia Agrícola, v.30, p.1012-1022, 2010.

TARJUELO, J.M. El riego por aspersión y su tecnologia. 3 ed. Madrid: Editorial Mundi Prensa, 2005. 581p. 